\title{
Pobreza e desigualdade de renda em Belo Horizonte: uma análise para setores de habitação
}

Maria Laura de Resende Paiva ${ }^{1}$

André Braz Golgher ${ }^{2}$

\begin{abstract}
Resumo: Os elevados níveis de desigualdade de renda e de pobreza existentes no Brasil podem também ser observados para dados municipais e em recortes geográficos menores. Este estudo contrastou ambas variáveis para dois setores habitacionais distintos do município de Belo Horizonte: o setor normal não-favela - e o especial ou subnormal - vilas, aglomerados e favelas. Para tanto, estimaram-se equações mincerianas de rendimentos com o uso da técnica dos Mínimos Quadrados Ordinários, observando se existiam diferenças significativas nos rendimentos de trabalhadores que fossem correlacionadas ao local de residência. Além disso, calculou-se a proporção de pobres e o Índice de Gini para os setores citados. Estes foram utilizados como base comparativa para as microsimulações contrafactuais que simularam como que fatores relacionados à localização da residência e à desigualdade de escolaridade existentes entre os setores impactavam em ambos indicadores. Observou-se que as reduções na desigualdade de renda e no número de pobres em Belo Horizonte foram mais acentuadas em decorrência do aumento fictício da escolaridade do setor subnormal do que do aumento da renda estimado por fatores correlacionados à localização da moradia.
\end{abstract}

Palavras-chave: favelas, desigualdade de renda, escolaridade, pobreza.

\section{Poverty and income inequality in Belo Horizonte: an analysis by place of residence}

\begin{abstract}
Brazil is one of the most unequal countries regarding income distribution. A consequence of this inequality is that although Brazil is a middle income country, poverty levels are quite high when compared to countries with

1 Bacharel em Economia pela FACE/UFMG. E-mail: marialaura.paiva@gmail.com.

2 Professor do Cedeplar/FACE/UFMG: E-mail: agolgher@cedeplar.ufmg.br.
\end{abstract}


similar per capita income levels. This paper discusses these subjects for the municipally of Belo Horizonte. In order to do so, we compared the normal sector with the special or subnormal one, which is composed by slums and comparable areas. We estimated Micerian income equations for workers in both residential sectors so as to apprehend if there were differences in wages that were correlated with place of residence. Moreover, we estimated the proportion of poor people and the Gini index for both areas. Besides that, counter-factual microsimulations simulated the impacts on poverty and inequality levels if schooling levels in both sector of residence were similar, and also if the disadvantages related to place of residence did not exist. We observed that the influence of educational differences were much more significant than the ones related to sector of residence.

Key-words: slums, income inequality, schooling, poverty.

JEL: J01, J24, J70

\section{Introdução}

A elevada desigualdade de renda existente no Brasil tem sido tema de vários estudos que buscam aprofundar o conhecimento sobre suas origens, e visam explicar as razões para tal acontecimento e propor possíveis soluções para seu fim (Barros et al. 2000a; Hoffman, 2000; Ferreira \& Litchfield 2000). Isso ocorre em parte devido à situação relativamente desfavorável em que o país se encontra em comparações internacionais (Patu 2006), e também devido ao fato que o nível de desigualdade parece ter efeitos negativos sobre o desempenho agregado da economia (Cerqueira 2004; Ferreira \& Litchfield 2000).

Segundo Barros et al. (2000a), as últimas décadas foram marcadas por um elevado e constante grau de desigualdade na distribuição de renda. Como exemplo, o índice de Gini da renda dos chefes de domicílio era igual a 0,609 para o Brasil (FIBGE 2000). Apenas muito recentemente que se observou uma leve melhora nestes indicadores (IBRE/FGV 2005).

Decorrente desta elevada desigualdade de renda, apesar do Brasil estar entre um terço dos países mais ricos do mundo em termos de renda per capita (Barros et al. 2002a), são elevados os níveis de pobreza no país, com valores superiores a outros países com renda média similares. Vários estudos sobre as possíveis causas da desigualdade de renda e pobreza foram escritos. Por exemplo, segundo Rocha (2003), pobreza e desigualdade de renda são duas faces do mesmo problema.

De forma geral, três fatores são sistematicamente utilizados para explicar tendências nos níveis de desigualdade e pobreza: crescimento econômico, desigualdade de renda e estrutura familiar. Esses dois primeiro tópicos foram extensivamente discutidos, por exemplo, por Barros et al. (2000a) e por Ravalion (2001). Com relação ao terceiro desses 
pontos ver Iceland (2003a e 2003b), e para dados para o Brasil, ver Golgher (2008).

Quanto à desigualdade de renda, ponto discutido neste trabalho, entre os pioneiros está o debate entre Fishlow e Langoni (Ferreira \& Litchfield 2000), que analisaram a importância da educação e do funcionamento do mercado de trabalho como determinante da distribuição de renda no Brasil.

Barros \& Mendonça (1995) fizeram uma decomposição da desigualdade salarial, através da contribuição de cada fonte para a desigualdade observada. Assim puderam reconstituir a origem de quase $60 \%$ do total da desigualdade observada. $\mathrm{O}$ resultado obtido mostrou que uma divisão da sociedade entre grupos com níveis diferentes de escolaridade responde por entre um terço e a metade da desigualdade total, mesmo levando em consideração o fato dessas pessoas terem cores diversas, trabalharem em regiões diferentes e terem níveis de experiências variados. Existe, portanto, uma proeminência da educação como determinante da renda e, conseqüentemente, da pobreza e desigualdade de renda.

Portando, uma forma de diminuir a pobreza e aumentar a igualdade e mobilidade social, além de ser essencial para fomentar o crescimento econômico, seria a expansão educacional (Barros et al. 200ob). Essa expansão aumentaria a produtividade do trabalho e contribuiria para o crescimento econômico, aumentando os salários e diminuindo a pobreza.

A segmentação do mercado de trabalho também constitui uma fonte de dispersão de rendimentos ao provocar uma remuneração distinta a trabalhadores com mesmo potencial produtivo, sem critério explícito, ou ainda devido a atributos não produtivos como cor e sexo que provocam uma diferenciação no mercado de trabalho (Ramos \& Vieira 2000). Um estudo feito por Barros e Mendonça (1996) confirmou a segmentação do mercado de trabalho brasileiro, constatando que o setor formal e o informal possuem remunerações distintas, mesmo quando os trabalhadores possuem características semelhantes.

A elevada desigualdade de renda observada para o Brasil, também pode ser notada em diversas regiões do país. O estado de Minas Gerais possuía em 2000 um índice de Gini ligeiramente inferior ao do país, igual a 0,597 (Simão 2004), mas ainda assim com valores elevados. A Região Metropolitana de Belo Horizonte (RMBH) apresentava valores um pouco mais elevados do que os observados acima para esse mesmo ano, o,63, superior ao de outras regiões metropolitanas brasileiras (Machado et al. 2004). Em estudos mais localizados, Cerqueira (2004) estimou a desigualdade de renda para a $\mathrm{RMBH}$ e para o município de 
Belo Horizonte para dados do Censo Demográfico de 2000 e constatou que o primeiro era menos desigual que o segundo. Este último autor mostrou ainda que existiam marcantes disparidades entre as áreas de planejamento do município de Belo Horizonte.

Assim, percebe-se que a desigualdade e pobreza podem ser analisadas em diferentes recortes geográficos de análise, inclusive para dados desagregados para áreas específicas de municípios. Uma maneira capaz de revelar relações entre a diferença de rendimentos, pobreza e desigualdade em uma perspectiva espacial para dados municipais é a comparação entre os setores de habitação de um município, como o setor subnormal - favela e assemelhados - e o restante da população - o setor normal.

As favelas surgiram com a ocupação dos espaços vazios localizados próximos aos centros urbanos devido às limitações impostas pela distância e pelos altos custos de transporte (Silva 200o) e, em grande parte dos casos, decorrem da ocupação informal da terra com precariedade dos serviços de esgoto, coleta de lixo e abastecimento de água. Com moradias precárias, infra-estrutura básica insatisfatória e elevados índices de violência, as vilas e favelas retratam a exclusão social e também a segregação espacial (Lemos 2004).

Outro aspecto que exemplifica essa exclusão seria a grande desigualdade educacional que pode ser observada entre a população residente nas favelas e vilas e nos demais bairros de uma localidade (Ribeiro \& Lago 2001). Segundo Pasternak (2000), a população das favelas de São Paulo é menos escolarizada que a do município como um todo. Em 1991, considerando a população moradora de vilas e favelas acima de cinco anos de idade, $26 \%$ não sabia ler nem escrever. Para a população municipal, esta porcentagem era igual a $10,6 \%$.

Essa diferenciação nos níveis educacionais impacta diretamente nas possibilidades de inserção no mercado de trabalho e nos rendimentos auferidos. A relação entre níveis educacionais, rendimentos e local de moradia foi abordado em um estudo feito para as favelas do Rio de Janeiro (Pero et al. 2005). Os autores verificaram através de equações de rendimentos que havia uma diferenciação salarial entre moradores e não moradores de favelas. Quando comparados trabalhadores com características similares - em termos de sexo, raça, escolaridade e idade aqueles que moravam no setor subnormal recebiam cerca de $47 \%$ a menos que aqueles que moravam na zona sul fora das favelas.

De forma similar ao analisado por Pero et $A L$. (2005), o objetivo do presente trabalho é avaliar se trabalhadores com características semelhantes possuem salários diferentes por causa de fatores relacionados ao fato de morarem em vilas e favelas ou não. Avaliou-se se esses dife- 
renciais impactavam nos níveis de renda e pobreza dos setores de residência em Belo Horizonte.

Para tanto, este texto foi dividido em seis partes, incluindo essa introdução. A próxima contém a metodologia empregada nas análises econométricas, que são equações de rendimentos ou mincerianas aplicadas aos dados do Censo Demográfico de 2000 e estimadas pelo método dos Mínimos Quadrados Ordinários (MQO). Variáveis que influenciam a determinação do rendimento auferido foram inseridas no modelo, como: a idade, o sexo, a cor, educação, tipo de trabalho exercido e o setor econômico da atividade desempenhada. Uma dummy que informa o tipo de setor habitado foi inserida para atingir o objetivo principal deste trabalho que é verificar a existência de diferenciação de rendimentos que seja correlacionado com o local de habitação - se em vilas e favelas ou não. Em seguida, apresenta-se uma análise descritiva dos dados, que é baseada nas discussões metodológicas e que também fundamentam o contexto para a discussão dos resultados. A seção 3 apresenta as análises das análises econométricas e os resultados obtidos. O Índice de Gini e o Índice de Pobreza, este último medido através da proporção de pobres, foram calculados tanto para Belo Horizonte como para seus setores separadamente e são apresentados na seção seguinte. Além disso, tendo como base as análises econométricas descritas acima, duas microsimulações foram feitas com o objetivo de verificar o impacto de duas realidades contrafactuais nestes indicadores. A conclusão encerra o texto.

\section{Metodologia}

De forma geral, moradores de favelas e de áreas desfavorecidas em termos urbanísticos e ambientais apresentavam características médias distintas dos demais, com menores níveis de educação e renda. Essas áreas são definidas no Censo Demográfico de 2000 (FIBGE 2000) como setor subnormal e são caracterizadas como:

conjunto (favelas e assemelhados) constituído por unidades habitacionais (barracos, casas etc.), ocupando, ou tendo ocupado até período recente, terreno de propriedade alheia (pública ou particular), dispostas, em geral, de forma desordenada e densa, e carentes, em sua maioria, de serviços públicos essenciais.

Pretende-se neste texto aprofundar essa discussão com a utilização de equações de rendimento e de microsimulações comparando o setor subnormal com o dito normal ou não especial. Aqui é discutida a metodologia empregada na estimação destas primeiras. 
Motivado pela teoria do capital humano proposta por Mincer (Resende \& Wyllie 2006), as equações de rendimento foram estimadas com o objetivo principal de analisar se trabalhadores com características análogas possuem salários diferentes dado ao fato de morarem em vilas e favelas, setor subnormal, ou não, setor normal ${ }^{3}$. A seguinte equação de rendimentos minceriana foi utilizada:

$$
\text { (1) } \quad \operatorname{Ln}\left(w_{i}\right)=\hat{a}+\hat{a} X_{i}^{\prime}+\tilde{a} Y_{i}+u_{i}
$$

Em que: $w_{i}$ representa o rendimento de cada indivíduo $i$ por hora trabalhada, $\hat{a}$ é o vetor de coeficientes, $X$ é o vetor contendo variáveis independentes que influenciam o rendimento do indivíduo, $Y$ representa a dummy para o local de habitação, favela ou não-favela, ã é o coeficiente desta dummy e $u_{i}$ é o erro estocástico.

Para estimar a equação (1) foi usado o método dos Mínimos Quadrados Ordinários (MQO) e o pacote estatístico SPSS, pacote também usado em todas as análises descritivas. Outros estudos similares, como Sachsida et al (2004) e Trostel et al. (2002), também utilizam o mesmo modelo econométrico, dentre muitos outros.

Os microdados utilizados como base de dados provêm do Censo Demográfico de 2000 (FIBGE 2000). Os dados usados neste estudo são do município de Belo Horizonte, que contém 226.691 observações na amostra, que quando expandida representa 2.227.873 indivíduos. Porém, para a análise econométrica foram empregados filtros para melhor adequação da amostra aos escopos deste trabalho. Dado que o objetivo principal é comparar os rendimentos entre os habitantes de favelas e não-favelas, os setores de habitação foram restringidos a esses dois. Foram desconsiderados os habitantes de alojamentos, aldeias indígenas, asilos, orfanatos e outros setores presentes na base de dados, sendo que todos possuíam baixa representatividade. Além disso, foram considerados apenas os indivíduos com rendimento positivo e com idade até 64 anos de idade. Os setores de atividades foram limitados ao industrial e ao de serviços, excluindo o setor agrícola devido à sua baixa representatividade em Belo Horizonte. Após essas adequações, a amostra foi reduzida para 91.806 observações, que expandida representava 907.218 indivíduos.

A variável dependente é expressa pelo logaritmo da renda de trabalho por hora. Assume-se que a variável tenha uma distribuição normal, como foi comprovado empiricamente (resultados não mostrados) para dados de Belo Horizonte em 2000.

3 A proposta aqui não é discutir se os moradores de favelas recebem menos por morarem em setores subnormais ou, a causalidade inversa, se moram em favelas por terem menores rendimentos. Além desses efeitos, outros, como fatores não-observados pelas variáveis dos modelos econométricos e que são relacionados ao local de moradia, são os de interesse nesta. 
Entre as variáveis que possuem influência mais significativa sobre a renda e foram utilizadas neste estudo estão: idade, sexo, cor, escolaridade, o tipo de trabalho exercido e o setor econômico da atividade desempenhada (Freguglia et al. 2007; Saschida et al. 2004). Alguns comentários a respeito de cada uma delas são tecidos a seguir.

Existe uma relação positiva entre a experiência do trabalhador e a renda auferida, porém a taxas decrescentes. Ou seja, a relação tende a ser crescente e côncava (Freguglia et al. 2007), como mostrado no gráfico 5 para Belo Horizonte. Para inserir esse efeito foi usada a variável idade como proxy da experiência e também o termo quadrático para captar a não-linearidade da relação experiência e renda (Antigo et al. 2006). Assume-se aqui que uma grande proporção de pessoas trabalha e estuda concomitantemente, e, assim, adquire experiência profissional enquanto aumenta a escolaridade.

A presença das variáveis sexo e cor como atributos não produtivos se justifica devido à influência destas sobre o rendimento do trabalhador. De forma geral, mulheres e pessoas negras, pardas ou indígenas recebem menos que homens e pessoas brancas ou amarelas (Soares 2000), como foi verificado anteriormente para Belo Horizonte. A dummy sexo possui valor igual a 1 para homens e o para mulheres. A dummy cor tem valor igual a 1 para brancos ou amarelos, e o para negros, pardos ou indígenas.

Dentre os atributos produtivos que causam diferenças salariais, destaca-se a educação (Ramos \& Vieira 2000). Sachsida et al (2004) mostram que essa variável possui relação positiva com o rendimento. Foi incluída uma variável numérica com os anos de estudo do indivíduo para captar esse efeito. Porém, essa relação tende a ser não-linear e convexa (Heckman et al 2003). Para captar essa convexidade, foram incluídas dummies para escolaridade, divididas conforme os anos estudados: zero a três, quatro a sete, oito a dez, onze, doze ou mais anos de estudo. Essa divisão foi feita para captar o efeito "diploma", em que os ganhos para cada ano de estudo não são constantes e os anos que representam os términos dos ciclos escolares possuem maiores retornos salariais (Crespo \& Reis 2006). Foi inserida ainda uma dummy para pessoas com treze ou mais anos de estudo e que tinham concluído curso, ou seja, que possuam, no mínimo, ensino superior completo.

A escolaridade de chefe do domicílio apresenta uma correlação com o nível de investimento na educação dos filhos (Saldanha Júnior \& Azzolini 2001) e, conseqüentemente, no rendimento auferido por estes. Como este efeito não pode ser observado completamente pelas variáveis acima, os anos de estudo deste foi também adicionado ao modelo. 
A segmentação do mercado de trabalho também constitui uma fonte de dispersão de rendimentos ao provocar uma remuneração distinta para trabalhadores com mesmo potencial produtivo (Ramos \& Vieira 2000; Barros \& Mendonça 1995; Ulyssea 2006; Néri 2002; Antigo et al. 2006). Para inserir essa característica no modelo foram incluídas seis dummies: uma para trabalhadores domésticos com carteira assinada e outra para os mesmo que não possuíam este documento; uma para empregados com carteira assinada e outra para os sem carteira; uma quinta dummy para empregadores; e outra para pessoas que trabalhavam por contaprópria.

O setor econômico em que o trabalho é exercido também pode influenciar a determinação dos rendimentos (Menezes-Filho 2002). Por isso, as atividades foram divididas em três setores: agrícola, industrial e de serviços. Devido ao baixo valor representado $(0,8 \%)$ em relação ao total, o setor agrícola foi desconsiderado. Foi assim obtida uma dummy com o valor 1 para ao setor industrial e o para o de serviços.

Todas essas variáveis são comumente utilizadas em equações de rendimentos mincerianas (Heckman et al. 2003). Como ponto central do trabalho, o modelo pretende analisar se trabalhadores com características similares possuem diferentes retornos salariais dado seu local de mora$\operatorname{dia}^{4}$ (se em favelas ou não), de forma similar ao estimado em Pero et al. (2005). Para isso, foi adicionada uma dummy que informa o tipo de setor habitado. Essa possui valor igual a 1 para aglomerado subnormal e o para o setor comum.

\section{Análise descritiva dos dados}

Em Belo Horizonte existem 209 vilas, favelas e assemelhados. Dentre as favelas mais antigas e conhecidas de Belo Horizonte estão: a Pedreira Prado Lopes, o aglomerado da Serra, o aglomerado Santa Lúcia, conhecido também como Morro do Papagaio, o Morro das Pedras, Cabana do Pai Tomás, Vista Alegre e Vila Cemig.

Segundo os dados do Censo Demográfico de 200o, o município de Belo Horizonte tinha aproximadamente $12 \%$ da população habitando setores especiais em aglomerados subnormais (favelas e assemelhados) e $88 \%$ em setor comum, quando desconsiderados os demais setores, que são pouco representativos. Como comparação, Pero et al. (2005) estimaram que os valores são respectivamente $20 \%$ e $80 \%$ para o Rio de Janeiro, cifras superiores ao observado em Belo Horizonte.

4Ver nota acima. 
A estrutura etária dos dois setores é bastante diferenciada. De forma geral, os moradores dos aglomerados subnormais são mais jovens que os demais, evidenciando níveis de fecundidade mais elevados. De fato, dentre estes $33,1 \%$ possui de zero a quatorze anos, enquanto que entre os moradores de áreas não-favela essa classe representava somente $23,1 \%$ da população. Para o grupo etário com idade entre quinze e 64 anos, a situação se inverte: estes são $70,3 \%$ da população no setor normal e $63,4 \%$ no subnormal. Nota-se também que a porcentagem de pessoas com idade igual ou superior a 65 anos é muito superior no setor normal quando comparada com o subnormal: 6,6\% entre os moradores deste primeiro setor e apenas $3,4 \%$ dos moradores de favelas.

Essa diferença na composição etária impacta diretamente nos níveis de pobreza. Os domicílios do setor subnormal tendem a apresentar uma participação maior de crianças e adolescestes que, em geral, diminuem a média de rendimentos per capita.

Existe um predomínio feminino em ambos os setores de habitação, mas principalmente para o setor normal, com razão de sexos de 89 ,o, enquanto que para o setor subnormal esse valor era de 95,o. Essa diferença é causada em parte devido à própria distribuição etária de cada um dos setores, uma vez que os homens predominam nas idades mais jovens e o contrário ocorre para as idades adultas e idosas. Entretanto, deve-se ressaltar que apesar do predomínio feminino ser menor no setor subnormal na RMBH, dadas as condições socioeconômicas diferenciadas em algumas dessas áreas, a proporção de domicílios em arranjos domiciliares com mulheres como chefe de domicílio e filhos é elevada (Golgher 2004b). Outro ponto a ser enfatizado é a alta taxa de mortalidade masculina de jovens em áreas subnormais (Prefeitura de São Paulo 2002), fato que também impacta na razão de sexos desses locais, apesar de que em direção contrária ao predomínio feminino menor dessas

áreas.

Outra característica bastante diferenciada entre os dois setores é a distribuição da população por cor (gráfico 1). Observa-se que mais da metade $(57,1 \%)$ dos moradores do setor normal se autodeclarou branco, sendo que o grupo dos pardos representava $35,26 \%$ da população do setor. Entre os moradores de favela, a cor predominante era a parda (53,3\%), enquanto que os brancos, com $31,17 \%$, eram minoritários. Além disso, a população negra representava $7,1 \%$ da população do setor comum e $14,9 \%$ do setor de aglomerado subnormal. 
GRÁFICO 1. DISTRIBUIÇÃO DA POPULAÇÃO POR COR DE BELO HORIZONTE

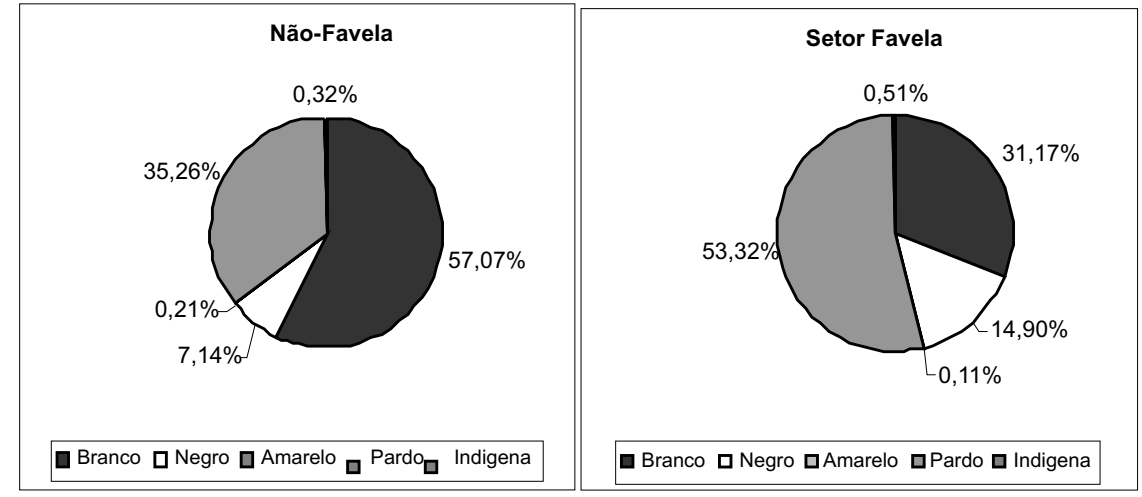

Fonte: Elaboração própria a partir dos microdados do Censo Demográfico, 2000.

Através da distribuição de rendimentos por cor mostrada no gráfico 2, observa-se que os brancos representavam $54,0 \%$ da população de Belo Horizonte e detiveram $74,7 \%$ dos rendimentos. Dentre os que se declararam de cor amarela, os números são respectivamente $0,19 \%$ e $0,33 \%$. Ou seja, as duas cores citadas recebem uma porcentagem de rendimentos maior que sua representatividade na população total ${ }^{5}$. Os demais pardos, negros e indígenas - possuem uma porcentagem de rendimentos menor que sua representatividade na população total, como também pode ser visto no gráfico 2. Elas representam conjuntamente $45,85 \%$ da população e recebem $25,00 \%$ do rendimento total.

GRÁFICO 2. DISTRIBUIÇÃO DE POPULAÇÃO E DE RENDIMENTO POR COR EM BELO HORIZONTE

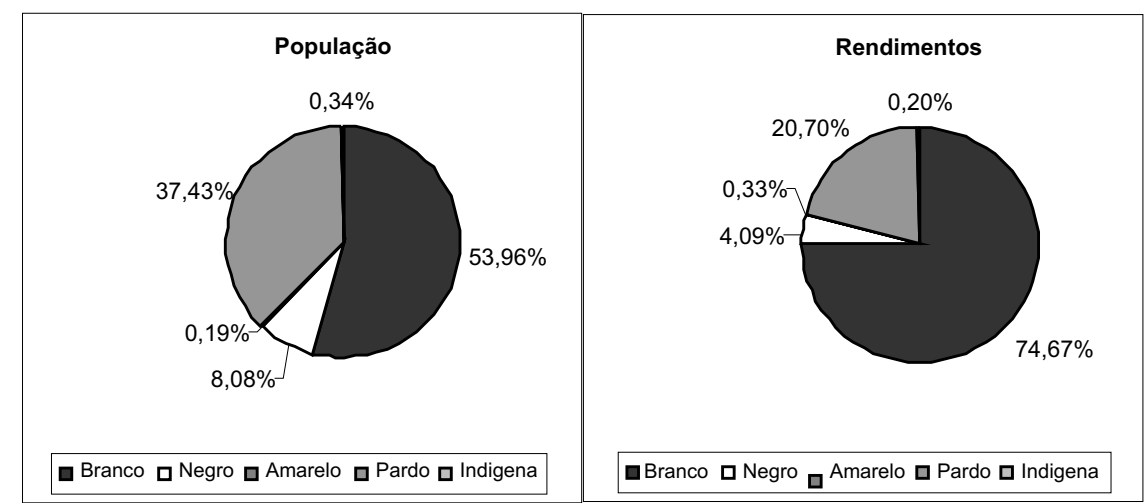

Fonte: Elaboração própria a partir dos microdados do Censo Demográfico, 2000.

5 Nas análises econométricas estas duas cores foram agrupados na dummy referente à cor, assim como as demais em um outro grupo. 
Essa diferenciação de rendimentos entre os grupos de cor e a distribuição dos mesmos nos diferentes setores de habitação pode ser verificada em uma outra perspectiva na distribuição da escolaridade entre os dois setores, que também é bastante diferenciada, e influenciada por diferenças na composição etária. Observa-se pelo gráfico 3 que a porcentagem de pessoas com escolaridade menor que o ensino fundamental (até sete anos de estudo) era superior entre os moradores de favelas, onde $81,7 \%$ dos seus habitantes possuem essa escolaridade. Dentre os moradores do setor normal essa classe representava $52,0 \%$ de sua população. Em contrapartida, para a escolaridade entre oito e dez anos de estudo, que corresponde ao Ensino Fundamental Completo ou Ensino Médio incompleto, as proporções eram $15,9 \%$ para os não moradores de favelas e $11,8 \%$ entre os moradores do setor subnormal. O grupo daqueles com onze anos de estudo engloba cerca de $18 \%$ dos não moradores de favelas e 5,6\% dos moradores. Para o grau de escolaridade superior a onze anos, ou seja, pelo menos Ensino Superior incompleto, a discrepância entre os setores se torna ainda maior, $14,1 \%$ entre os moradores do setor não-favela e $0,9 \%$ entre os moradores da favela. Considerando somente as pessoas que possuem escolaridade mínima igual ao ensino superior completo, cerca de $0,5 \%$ moram em favelas e $99,5 \%$ no setor comum.

GRÁFICO 3.DISTRIBUIÇÃO DA ESCOLARIDADE POR SETOR DE BELO HORIZONTE

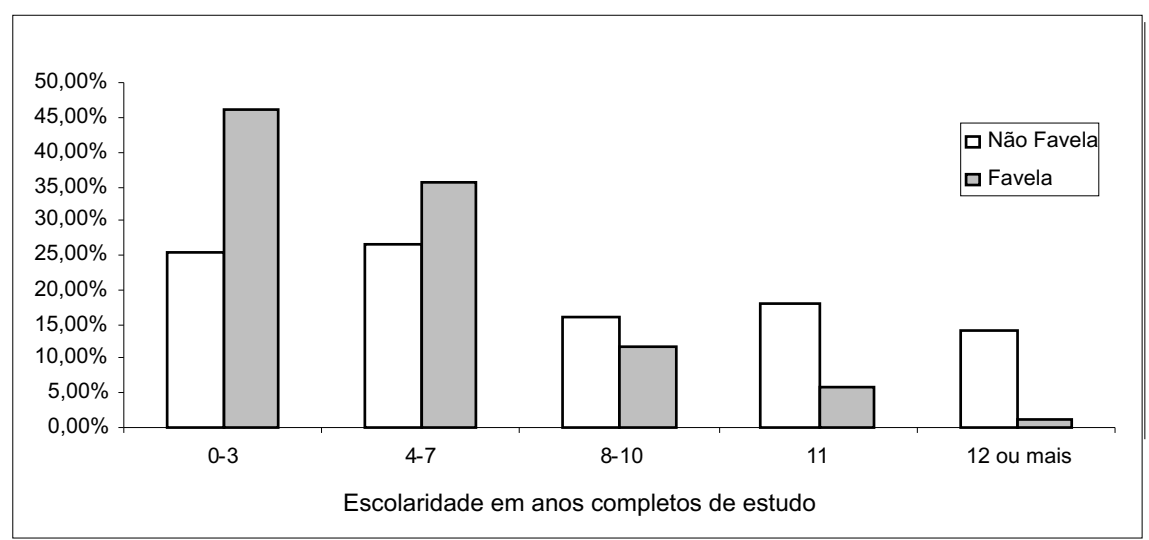

Fonte: Elaboração própria a partir dos microdados do Censo Demográfico, 2000.

A diferença de escolaridade entre os setores ou locais de moradia também pode ser vista pela escolaridade média (TAB 1) de cada um deles. Quando é considerado todo o município de Belo Horizonte, a escolaridade média é igual a 6,66 anos de estudo. Para os moradores do setor de não-favela esse valor era um pouco superior, 7,03 anos, e para o setor subnormal a escolaridade média era muito inferior de 3,97 anos. 
TABELA 1 - ESCOLARIDADE MÉDIA POR SETOR DE BELO HORIZONTE

\begin{tabular}{|c|c|c|c|}
\hline & $\begin{array}{l}\text { Belo } \\
\text { Horizonte }\end{array}$ & Não-favela & Favela \\
\hline Média(anos) & 6,66 & 7,03 & 3,97 \\
\hline
\end{tabular}

Fonte: Elaboração própria a partir dos microdados do Censo Demográfico (IBGE, 200o).

Analisando a escolaridade e o rendimento de homens e mulheres, moradores ou não de favelas, pode-se primeiramente observar o aumento da renda de trabalho com o aumento do número de anos estudados a taxas crescentes (gráfico 4). Nota-se também uma diferença entre homens e mulheres que moram em um mesmo setor, pois estas recebem menos que aqueles, mesmo possuindo a mesma escolaridade. Outra diferenciação que fica evidente no gráfico é a relacionada ao local de habitação. Os moradores de favelas, mesmo possuindo o mesmo sexo e a mesma escolaridade, recebem menos que os moradores do setor normal.

GRÁFICO 4. RENDIMENTO POR SEXO, POR SETOR E POR ESCOLARIDADE

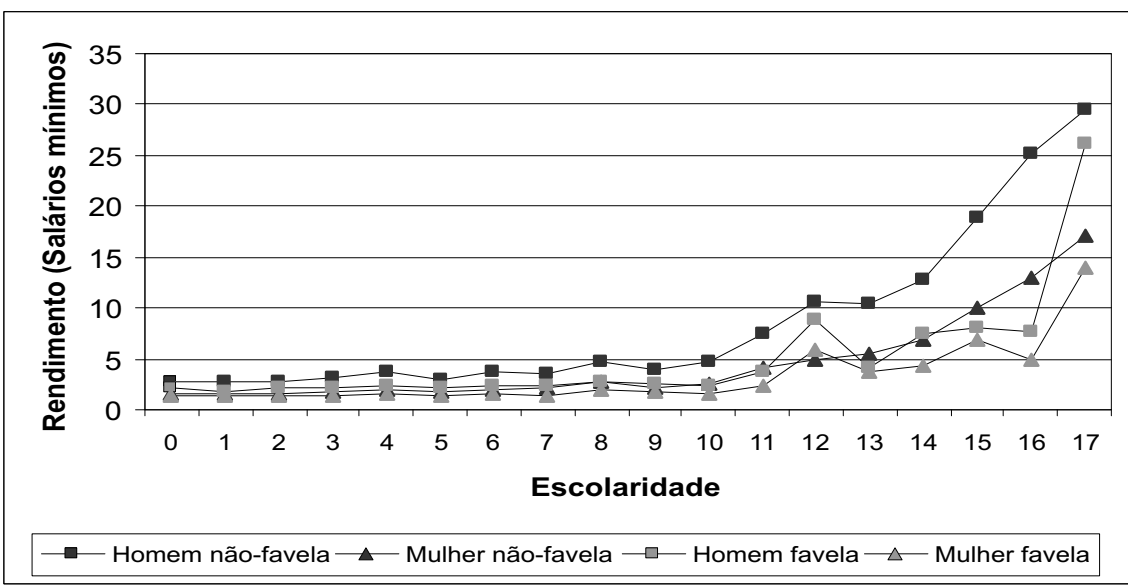

Fonte: Elaboração própria a partir dos microdados do Censo Demográfico (IBGE, 200o).

O gráfico 5 mostra a distribuição de rendimentos por faixa etária, por sexo e por setor de habitação. Observa-se que em todas as faixas etárias analisadas homens e mulheres do setor subnormal recebem menos que os do mesmo grupo do setor comum e que mulheres recebem menos que homens em um mesmo setor de moradia. Além disso, parece existir, principalmente para o setor normal, uma relação inicialmente crescente e possivelmente côncava entre os rendimentos e a idade. 
GRÁFICO 5. RENDIMENTO POR IDADE, POR SETOR E POR SEXO

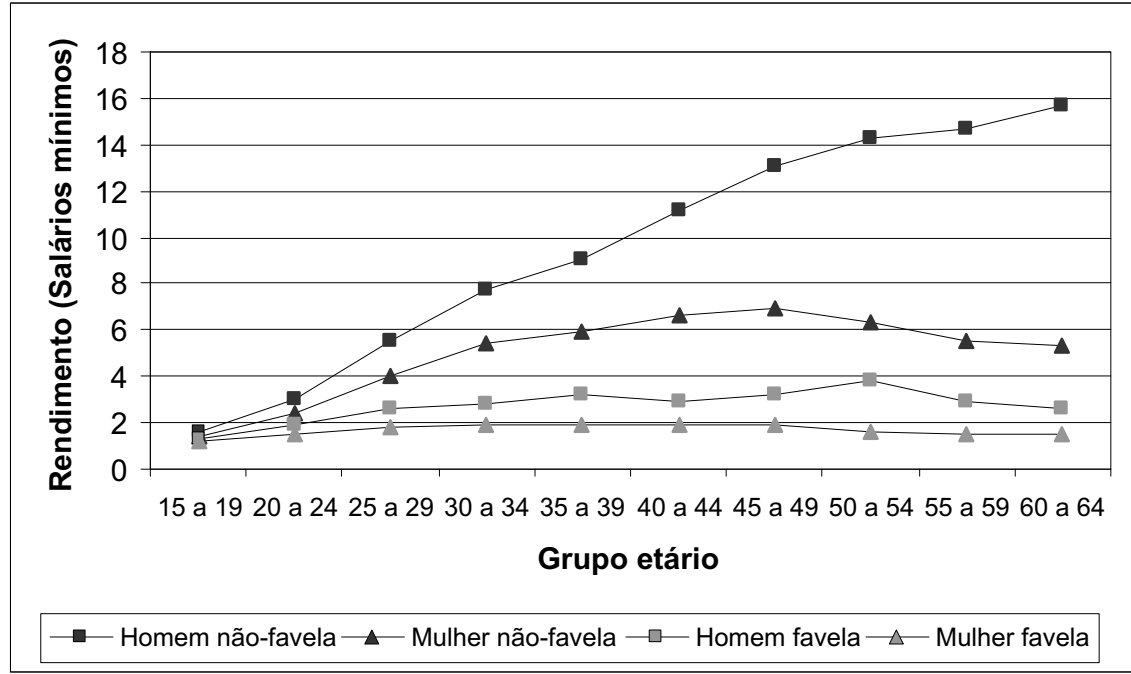

Fonte: Elaboração própria a partir dos microdados do Censo Demográfico, 2000.

O gráfico 6 mostra a proporção em cada faixa etária que tinha rendimentos positivos. Observa-se que, como esperado, as proporções para homens são superiores ao observado para mulheres. Além disso, os moradores em setores subnormais tendiam a apresentar proporções ligeiramente inferiores ao dos demais indivíduos, mas em tendências similares para ambos os sexos.

GRÁFICO 6. PROPORÇÃO COM RENDIMENTO POSITIVO POR IDADE, POR SETOR E POR SEXO

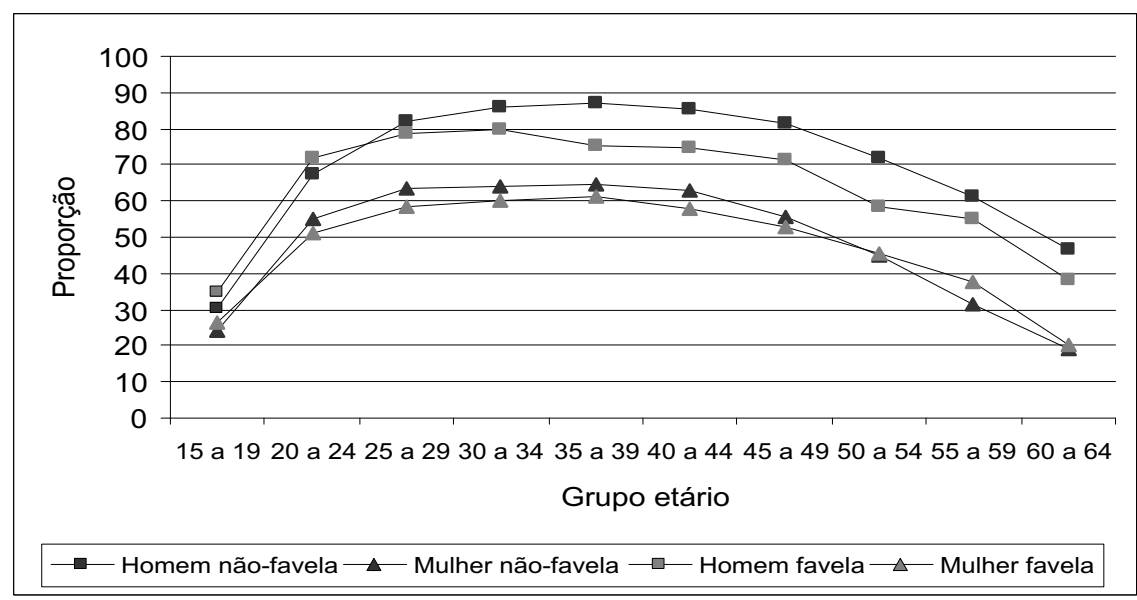

Fonte: Elaboração própria a partir dos microdados do Censo Demográfico (IBGE, 200o). 
A grande heterogeneidade dos trabalhadores é um dos fatores, dentre outros como os observados para diferenciais de cor, traduzidos pelo mercado de trabalho e transformada em diferença de rendimentos. A média do total de rendimentos em todos os trabalhos, medida em salários mínimos, é mais de três vezes superior entre os trabalhadores que não moram em favelas quando comparada com aqueles que moram (TABELA 2). A discrepância salarial entre os setores fica mais evidenciada pelo valor máximo dos rendimentos, que alcança um valor mais de 16 vezes superior para os não moradores de favelas. Note, porém, que a média do total de horas trabalhadas é mais igualitária entre os dois setores. Apesar do seu valor máximo ser superior no setor comum, o valor médio é ligeiramente superior no setor subnormal.

TABELA 2. RENDIMENTOS E HORAS TRABALHADAS PARA BELO HORIZONTE E POR SETOR DE HABITAÇÃO

\begin{tabular}{|c|c|c|c|c|c|c|}
\hline & \multicolumn{2}{|c|}{ Belo Horizonte } & \multicolumn{2}{|c|}{ Não-favela } & \multicolumn{2}{|c|}{ Favela } \\
\hline & Rendimento & $\begin{array}{c}\text { Horas } \\
\text { trabalhadas }\end{array}$ & Rendimento & $\begin{array}{c}\text { Horas } \\
\text { trabalhadas }\end{array}$ & Rendimento & $\begin{array}{c}\text { Horas } \\
\text { trabalhadas }\end{array}$ \\
\hline Média & 6,42 & 43,59 & 6,92 & 43,48 & 2,19 & 44,56 \\
\hline
\end{tabular}

Fonte: Elaboração própria a partir dos microdados do Censo Demográfico (IBGE, 200o).

A tabela 3 mostra a diferenciação entre os setores conforme o tipo de ocupação. Os trabalhadores domésticos representavam 19,36\% da população da favela e $7,11 \%$ do setor de não-favela, indicando uma maior inserção dos primeiros em ocupações com menor remuneração. A porcentagem de empregados, somando os com e sem carteira, nos dois setores é similar: $65,64 \%$ no setor comum e $62,23 \%$ no setor aglomerado subnormal. Para a proporção dos contra própria, os valores também são semelhantes, 21,97\%, para o setor normal e 17,68\% para o subnormal. Porém, a discrepância maior entre os setores está na proporção de empregadores. Esses representam $5,28 \%$ da população de não-favela e $0,74 \%$ da população das favelas. 
TABELA 3. DISTRIBUIÇÃO DE RENDIMENTOS POR TIPO DE OCUPAÇÃO POR SETOR

\begin{tabular}{|c|c|c|}
\hline $\begin{array}{l}\text { Trabalho } \\
\text { exercido }\end{array}$ & Não-favela & Favela \\
\hline $\begin{array}{l}\text { Doméstico com } \\
\text { carteira }\end{array}$ & $3,71 \%$ & $9,51 \%$ \\
\hline $\begin{array}{l}\text { Doméstico sem } \\
\text { carteira }\end{array}$ & $3,40 \%$ & $9,85 \%$ \\
\hline $\begin{array}{l}\text { Empregado } \\
\text { com carteira }\end{array}$ & $45,16 \%$ & $46,25 \%$ \\
\hline $\begin{array}{l}\text { Empregado } \\
\text { sem carteira }\end{array}$ & $20,48 \%$ & $15,98 \%$ \\
\hline Conta Própria & $21,97 \%$ & $17,68 \%$ \\
\hline Empregador & $5,28 \%$ & $0,74 \%$ \\
\hline
\end{tabular}

Essa apresentação descritiva de dados pretendeu caracterizar os diferentes setores de habitação em Belo Horizonte e introduzir as diversas variáveis que serão utilizadas nos modelos econométricos, como discutido na metodologia descrita na seção anterior.

\section{Análises econométricas}

Como discutido na metodologia, utilizando uma subamostra dos dados do Censo 2000 para Belo Horizonte, foram estimados três modelos econométricos. Esses se diferenciam pela quantidade de variáveis independentes inseridas. A TABELA 4 mostra os resultados obtidos em cada modelo, estimados com 91.806 observações sem a utilização dos pesos de expansão da amostra para que a variância dos dados não fosse subestimada.

No primeiro modelo, inseriu-se variáveis que espelham as características natas do trabalhador como idade, sexo e cor. Também foram adicionadas as variáveis que indicam a escolaridade e o local de moradia do indivíduo. Cada um dos coeficientes das variáveis incluídas no modelo 1 é discutido a seguir. Note que todas as variáveis em todos os modelos com uma única exceção foram significativas em $5 \%$.

A variável idade apresenta um coeficiente com sinal positivo, o que determina que, uma vez mantidos os efeitos das demais variáveis no modelo, quanto maior a idade maior tende a ser o rendimento auferido. 
Porém, sua versão ao quadrado possui sinal negativo, indicando que a relação entre elas cresce a uma taxa decrescente ${ }^{6}$. Ou seja, a relação é côncava, como previsto na discussão metodológica. Os outros dois modelos também apresentaram resultados semelhantes.

Os coeficientes positivos para as variáveis sexo e cor também condizem com a teoria aqui explicitada. Homens tendem a receber mais que mulheres, e pessoas da cor branca ou amarela apresentam uma tendência a receber rendimentos maiores que aqueles da cor parda, negra ou indígena, depois de controlados os efeitos das demais variáveis do modelo. Observa-se que essas variáveis também possuem coeficientes semelhantes nos três modelos. Tendo como base o modelo 3 e através do exponencial dos coeficientes obtidos, homens tendiam a receber $31 \%$ a mais que mulheres, e brancos e amarelos, $14 \%$ a mais que pardos, negros e indígenas.

Em concordância com o que foi discutido anteriormente e verificado no gráfico 6 , o coeficiente obtido pelo primeiro modelo para a escolaridade apresentou uma relação positiva com a renda. Ou seja, o rendimento tende a ser maior com o aumento da escolaridade.

A dummy para o local de habitação (se em vilas e favelas ou não), mesmo controlando pelas demais variáveis, exibiu uma relação negativa com a renda auferida. Isso indica que trabalhadores que habitam o setor subnormal possuem rendimentos menores que os demais que vivem no setor normal, mesmo que tenham características observáveis semelhantes. Esse resultado é também reflexo de fatores não observados correlacionados ao local de moradia do indivíduo. Por exemplo, a qualidade educacional média dos moradores das localidades subnormais pode ser inferior ao do restante da população.

No segundo modelo foram inseridas as dummies para a escolaridade, que, como discutido, tentam captar a convexidade da relação entre escolaridade e renda. Como já discutido, as divisões das dummies foram feitas conforme os ciclos de ensino no Brasil. A escolaridade do chefe do domicílio também foi inserida no modelo.

Observa-se que a variável escolaridade teve seu coeficiente reduzido. Isso ocorreu devido à captação de parte do efeito da escolaridade no rendimento também através das dummies que representam cada nível escolar. A dummy que representa escolaridade entre quatro e sete anos de estudo foi automaticamente excluída do modelo, indicando que os demais coeficientes foram obtidos em relação a ela. Os coeficientes para as dummies que representam escolaridade de doze anos ou mais de es-

6 Uma relação quadrática assim pode apresentar um máximo no intervalo de idades estudado dependendo dos coeficientes das variáveis. 
tudo e que representava o ensino superior completo são bastante elevados em relação aos demais. Os sinais relativos aos coeficientes das dummies refletem a convexidade da relação existente entre escolaridade e rendimento, como discutido no capítulo metodológico e observado no gráfico 4.

A escolaridade do chefe do domicílio também se relaciona positivamente com o rendimento do indivíduo. Isso indica a existência de fatores diversos que também influenciam o rendimento auferido do indivíduo e que se relacionam com a escolaridade do chefe do domicílio.

Mesmo com a inserção das dummies da escolaridade e da escolaridade do chefe do domicílio, o coeficiente para a dummy favela apresentou valor negativo e bastante próximo àquele do primeiro modelo, indicando a robustez do resultado.

TABELA 4. EQUAÇÕES DE RENDIMENTO

\begin{tabular}{|c|c|c|c|c|c|c|c|}
\hline & \multicolumn{2}{|c|}{ Modelo 1} & \multicolumn{2}{|c|}{ Modelo 2} & \multicolumn{3}{|c|}{ Modelo 3} \\
\hline & Coeficiente & $\begin{array}{l}\text { Desvio } \\
\text { Padrão }\end{array}$ & Coeficiente & $\begin{array}{l}\text { Desvio } \\
\text { Padrão }\end{array}$ & Coeficiente & $\begin{array}{l}\text { Desvio } \\
\text { Padrão }\end{array}$ & $\begin{array}{l}\text { Exp. } \\
\text { (Coef.) }\end{array}$ \\
\hline (Constante) & $-6,0360$ & 0,0225 & $-5,5639$ & 0,0264 & $-5,4479$ & 0,0270 & \\
\hline Idade & 0,0880 & 0,0013 & 0,0763 & 0,0012 & 0,0742 & 0,0012 & \\
\hline $\begin{array}{l}\text { Idade ao } \\
\text { quadrado }\end{array}$ & $-0,0008$ & 0,0000 & -0,0007 & 0,0000 & $-0,0007$ & 0,0000 & \\
\hline Sexo & 0,3136 & 0,0048 & 0,3211 & 0,0046 & 0,2672 & 0,0049 & 1,31 \\
\hline Cor & 0,2067 & 0,0051 & 0,1514 & 0,0050 & 0,1287 & 0,0050 & 1,14 \\
\hline Escolaridade & 0,1365 & 0,0006 & 0,0725 & 0,0026 & 0,0665 & 0,0025 & 1,07 \\
\hline $\begin{array}{c}\text { Escolaridade } \\
\text { 0-3 anos }\end{array}$ & - & - & 0,0770 & 0,0124 & 0,0878 & 0,0123 & 1,09 \\
\hline $\begin{array}{l}\text { Escolaridade } \\
8-10 \text { anos }\end{array}$ & - & - & $-0,0426$ & 0,0112 & $-0,0538$ & 0,0111 & 0,95 \\
\hline $\begin{array}{c}\text { Escolaridade } \\
=11 \text { anos }\end{array}$ & - & - & 0,1083 & 0,0162 & 0,0815 & 0,0160 & 1,08 \\
\hline $\begin{array}{l}\text { Escolaridade } \\
\text { ?12 anos }\end{array}$ & - & - & 0,3158 & 0,0238 & 0,3001 & o,0235 & 1,35 \\
\hline $\begin{array}{l}\text { Ens. Superior } \\
\text { Completo ou }+\end{array}$ & - & - & 0,2772 & 0,0123 & 0,2742 & 0,0121 & 1,32 \\
\hline $\begin{array}{l}\text { Escolaridade } \\
\text { chefe domicílio }\end{array}$ & - & - & 0,0356 & 0,0007 & 0,0361 & 0,0007 & 1,04 \\
\hline $\begin{array}{c}\text { Setor } \\
\text { Industrial }\end{array}$ & - & - & - & - & 0,0517 & 0,0059 & 1,05 \\
\hline $\begin{array}{l}\text { Doméstico com } \\
\text { carteira }\end{array}$ & - & - & - & - & $-0,2617$ & 0,0121 & 0,77 \\
\hline
\end{tabular}

continua 
TABELA 4. EQUAÇÕES DE RENDIMENTO

\begin{tabular}{|c|c|c|c|c|c|c|c|}
\hline \multicolumn{3}{|c|}{ Modelo 1} & \multicolumn{2}{|c|}{ Modelo 2} & \multicolumn{3}{|c|}{ Modelo 3} \\
\hline & Coeficiente & $\begin{array}{l}\text { Desvio } \\
\text { Padrão }\end{array}$ & Coeficiente & $\begin{array}{l}\text { Desvio } \\
\text { Padrão }\end{array}$ & Coeficiente & $\begin{array}{l}\text { Desvio } \\
\text { Padrão }\end{array}$ & $\begin{array}{l}\text { Exp. } \\
\text { (Coef.) }\end{array}$ \\
\hline $\begin{array}{c}\text { Doméstico } \\
\text { sem carteira }\end{array}$ & - & - & - & - & $-0,2226$ & 0,0125 & 0,80 \\
\hline $\begin{array}{l}\text { Empregado } \\
\text { sem carteira }\end{array}$ & - & - & - & - & 0,0022 & 0,0061 & 1,00 \\
\hline Empregador & - & - & - & - & 0,5023 & 0,0113 & 1,65 \\
\hline $\begin{array}{c}\text { Conta } \\
\text { Própria }\end{array}$ & - & - & - & - & 0,0397 & 0,0061 & 1,04 \\
\hline FAVELA & $-0,1250$ & 0,0081 & $-0,1243$ & 0,0079 & $-0,1073$ & 0,0078 & 0,90 \\
\hline R2 Ajustado & \multicolumn{2}{|c|}{0,521} & \multicolumn{2}{|c|}{0,553} & & 0,566 & \\
\hline
\end{tabular}

Fonte: Elaboração própria a partir dos microdados do Censo Demográfico (IBGE 200o). Nota: As variáveis em negrito não são significativas em $5 \%$.

No terceiro modelo foram incluídas as dummies para o tipo de ocupação e para o setor econômico do trabalho. Nota-se que as variáveis que já estavam presentes no segundo modelo apresentaram valores semelhantes no terceiro modelo.

O coeficiente do setor industrial foi positivo, o que indica que trabalhadores do setor industrial, uma vez controlados os efeitos das demais variáveis, tendem a obter rendimentos superiores àqueles do setor terciário.

Cinco dummies detalham o tipo de ocupação do indivíduo. A dummy para empregados com carteira assinada foi excluída e os coeficientes dos demais tipos de trabalho foram obtidos em relação a ela. Nota-se que empregados domésticos, tanto com carteira assinada como sem, apresentam uma tendência a receber menos que empregados com carteira assinada. A situação se inverte para trabalhadores por conta própria e, principalmente, empregadores. Uma única variável foi não-significativa que foi a dummy para empregados sem carteira, sugerindo que estes e os com carteira tendiam a receber rendimentos semelhantes, uma vez controlados os efeitos das demais variáveis.

Note que a dummy favela apresentou um coeficiente negativo e significativo também neste modelo. Segundo o exponencial deste coeficiente, os trabalhadores do setor subnormal quando comparados com outros similares, conforme as variáveis incluídas no modelo, com restante do município tendiam a receber aproximadamente $10 \%$ a menos.

Este terceiro modelo será utilizado como base para as microsimulações apresentadas na seção seguinte. 


\section{Microsimulações contrafactuais}

Nesta seção são apresentados dois tipos de microsimulações contrafactuais. Nesse tipo de simulação, como explorada neste texto, os microdados da base de dados são modificados, sendo criada uma nova realidade contrafactual, que seria observada caso algum fenômeno ocorresse e todo o restante fosse mantido constante.

A primeira microsimulação foi feita alterando-se diretamente a renda proveniente do trabalho dos moradores do setor subnormal. Esses rendimentos dos moradores de vilas e favelas tendem a ser menores que os dos moradores do setor normal. Esse fato é causado por uma série de fatores, tais como menores níveis de educação ou maiores proporções de pretos, pardos e indígenas. Uma estimativa dessa redução relacionada ao rendimento proveniente do trabalho, que é correlacionada ao fato do indivíduo morar ou não em uma favela, pode ser obtida pelo coeficiente da dummy favela do terceiro modelo. Para retirar esse efeito, os rendimentos de trabalho dos moradores de favela foram multiplicados pelo inverso do exponencial do coeficiente da dummy favela $(1,11)$. Os rendimentos do trabalho para os indivíduos que moram no setor normal não foram alterados. Depois disso, uma vez obtidas as novas rendas de trabalho, as rendas domiciliares per capita contrafactuais foram estimadas. Essas últimas foram obtidas agregando as novas rendas de trabalho e todos os demais tipos de renda para cada um dos domicílios nos dois setores de moradia.

A segunda microsimulação foi feita se alterando a escolaridade dos habitantes do setor subnormal. As escolaridades médias dos setores de favela e não-favela são bastante distintas, como mostrado na tabela 1, e isto exerce grande influência sobre os rendimentos auferidos (Ramos \& Vieira 2000). Para estimar a renda dos moradores da favela caso tivessem a mesma escolaridade média dos demais habitantes de Belo Horizonte, ou seja, daqueles que vivem nas áreas normais, a escolaridade dos moradores dos setores subnormais foi multiplicada pela razão entre a escolaridade média dos não moradores de favela e a escolaridade média dos moradores de favela. $\mathrm{O}$ mesmo procedimento foi feito para a escolaridade do chefe de família. Os valores superiores a dezessete anos de estudo, cerca de $1 \%$ do total, foram considerados como dezessete. As dummies para escolaridade foram então reclassificadas. Em seguida, de posse da escolaridade contrafactual, o rendimento do trabalho contrafactual para cada um dos indivíduos moradores nas favelas foi estimado a partir do modelo econométricos de número 3. Por fim, as rendas domiciliares per capita contrafactuais foram estimadas.

Os indicadores de pobreza e desigualdade foram, então, estimados para os valores observados e para as duas microsimulações contrafactuais. 


\section{1 Índice de Pobreza}

Mesmo quando existe consenso que a fonte mais apropriada para determinar a linha de pobreza é através de informações sobre o consumo das famílias (Rocha 2000), ela é usualmente determinada através de múltiplos do salário mínimo ou de algum outro indicador monetário, como um ou dois dólares por dia, por causa da simplicidade metodológica (Simão 2004), que foi a metodologia utilizada aqui.

Para estimar a proporção de pobres, calculou-se primeiramente a renda domiciliar per capita para os dados observáveis e para as duas microsimulações citadas. Foram classificados como pobres aqueles que viviam em um domicílio com rendimentos iguais ou inferiores a meio salário mínimo. Essa proporção de pobres provém do índice sintético de Foster, Greer e Thorbecke (FGT) calculado para á igual a zero (Liberato 2004). Os resultados são mostrados nas tabelas 5,6 e 7 , respectivamente para dados observados e as duas microsimulações.

Como esperado, a proporção de pobres observada em 2000 (TABELA 5) para os moradores de favelas $(38,0 \%)$ é bastante elevada quando comparada ao setor normal $(14,8 \%)$ e também ao município de Belo Horizonte $(17,5 \%)$.

TABELA 5. DISTRIBUIÇÃO DA POPULAÇÃO POBRE: DADOS OBSERVADOS

\begin{tabular}{ccc}
\hline & Pobres & Não pobres \\
Belo Horizonte & $17,52 \%$ & $82,48 \%$ \\
Não-favela & $14,77 \%$ & $85,23 \%$ \\
Favela & $38,01 \%$ & $61,99 \%$ \\
\hline
\end{tabular}

Fonte: Elaboração própria a partir dos microdados do Censo.

A tabela 6 mostra os resultados obtidos na primeira microsimulação, ou seja, caso trabalhadores semelhantes, tanto na favela como no restante do município, tivessem o mesmo rendimento. Apesar da porcentagem de pobres de Belo Horizonte ter sofrido uma ligeira diminuição, passando de $17,5 \%$ (tabela 5 ) para $16,8 \%$ (tabela 6 ), a redução no setor subnormal foi relativamente elevada, de $38,0 \%$ para $32,3 \%$. Assim, uma vez controlados os efeitos dos diferenciais de educação, cor, etc, se inexistisse a redução de rendimentos correlacionada ao local de moradia, haveria uma redução de cerca de $5 \%$ no número de pobres entre os moradores de favelas. 
TABELA 6. DISTRIBUIÇÃO DA POPULAÇÃO POBRE: $1^{\mathrm{a}}$ MICROSIMULAÇÃO

\begin{tabular}{ccc}
\hline & Pobres & Não pobres \\
Belo Horizonte & $16,84 \%$ & $83,16 \%$ \\
Não-favela & $14,77 \%$ & $85,23 \%$ \\
Favela & $32,28 \%$ & $67,72 \%$ \\
\hline
\end{tabular}

Fonte: Elaboração própria a partir dos microdados do Censo.

Na segunda microsimulação (tabela 7), observou-se que se a distribuição da escolaridade dos setores fosse mais igualitária, a porcentagem de pobres em cada setor também o seria, independente de outros fatores. Em Belo Horizonte, a porcentagem de pobres se reduziria de $17,5 \%$ para $14,8 \%$, e a do setor subnormal passaria de $38,0 \%$ para $16,4 \%$. Ou seja, a queda no número de pobres provocada pelo aumento fictício da escolaridade dos habitantes de favelas foi superior a $20,0 \%$ no setor subnormal.

TABELA 7. DISTRIBUIÇÃO DA POPULAÇÃO POBRE: $2^{\mathrm{a}}$ MICROSIMULAÇÃO

\begin{tabular}{ccc}
\hline & Pobres & Não pobres \\
Belo Horizonte & $14,85 \%$ & $85,15 \%$ \\
Não-favela & $14,77 \%$ & $85,23 \%$ \\
Favela & $16,43 \%$ & $83,57 \%$ \\
\hline
\end{tabular}

Fonte: Elaboração própria a partir dos microdados do Censo.

4.2 Coeficiente de Gini

Para quantificar o grau de concentração de renda existente em Belo Horizonte e em cada setor separadamente foi calculado o coeficiente de Gini para indivíduos com renda maior que zero. Ele pode ser visualizado no gráfico 7 , que mostra a Curva de Lorentz para os dois setores em separado. O eixo das abscissas representa a porcentagem da população e o das ordenadas a porcentagem da renda auferida por essa população acumulada. Assim, a diagonal do gráfico representa a perfeita distribuição de renda e a convexidade da curva de Lorentz indica o grau de desigualdade na distribuição (Pinho \& Vasconcellos 2003). O coeficiente de Gini é representado pela razão entre a área localizada entre a curva de Lorentz e a diagonal de perfeita igualdade e toda a área abaixo desta diagonal.

O coeficiente de Gini calculado para o setor de não-favela foi de 0,603 , bastante próximo ao valor encontrado para toda a cidade de Belo Horizonte, 0,607 . O coeficiente para o setor de favela era muito inferior, 
o,393, o que indica um menor grau de desigualdade de rendimentos entre seus habitantes. Esse resultado é condizente com a tabela 2, que mostra um menor valor para o desvio padrão dos rendimentos do setor de favela, indicando uma menor dispersão desses em relação ao valor médio encontrado em Belo Horizonte.

\section{GRÁFICO 7. CURVA DE LORENZ POR SETOR DE BELO HORIZONTE}

Favela - Coeficiente de Gini: 0,393

\section{Não-favela - Coeficiente de Gini: 0,603}
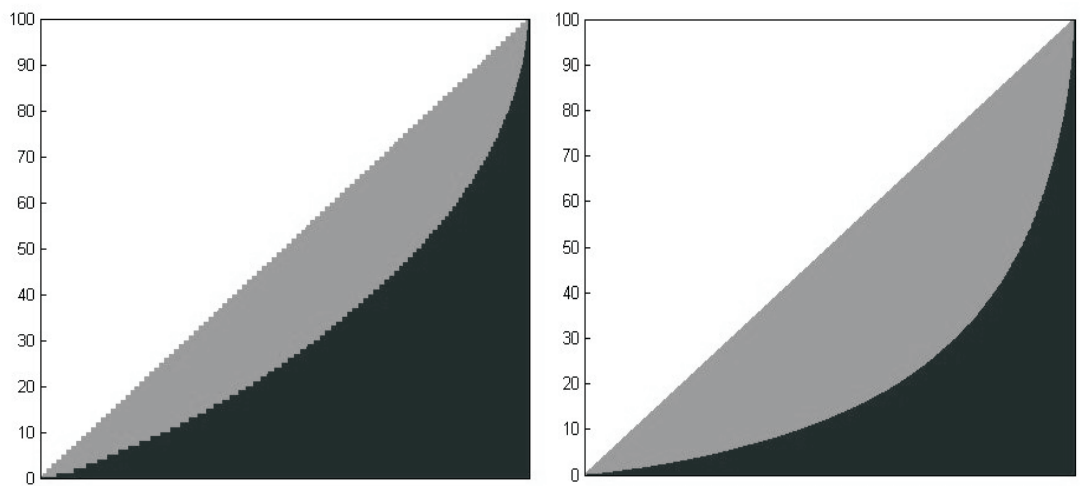

Fonte: Elaboração própria a partir dos microdados do Censo Demográfico (IBGE 2000).

Utilizando os resultados obtidos na primeira microsimulação, o coeficiente de Gini foi novamente calculado. O valor encontrado para Belo Horizonte sofreu uma pequena redução passando de 0,607 para 0,604.

Entretanto, a redução do índice do Gini foi mais expressiva na segunda microsimulação. Como previsto, houve uma redução da concentração de renda de Belo Horizonte provocada pelo aumento da escolaridade do setor subnormal. O índice de Gini encontrado reduziu-se para 0,597.

Nota-se que tanto a redução do número de pobres como a queda do índice de Gini em Belo Horizonte foi muito mais acentuada devido ao aumento fictício da escolaridade que ao aumento da renda do setor subnormal por fatores correlacionados à localização da moradia do indivíduo.

\section{Conclusão}

Como discutido, a desigualdade de rendimentos pode ser capitada também em âmbito municipal. Nesta última perspectiva, a diferença de rendimentos pode ser visualizada dentro do município através da análise de diferentes partes do mesmo, inclusive em comparações entre as favelas existentes com o restante da localidade. 
Como mostrado no texto, nas favelas de Belo Horizonte, a renda média era três vezes menor que a do setor de não-favela. Assim, por ter uma renda familiar per capita mais baixa, a desigualdade de renda, medida pelo coeficiente de Gini $(0,393)$, foi menor que a do setor de não-favela $(0,603)$ e que do município de Belo Horizonte como um todo $(0,607)$. A porcentagem de pessoas pobres foi mais elevada no setor subnormal, $38,01 \%$, que no setor normal, $14,77 \%$ e do que em Belo Horizonte, $17,52 \%$.

Por ser uma das causas mais importantes da desigualdade de renda, a escolaridade foi analisada mais detalhadamente. A desigualdade educacional existente entre os dois setores de habitação foi evidenciada pela diferença da escolaridade média entre os setores de habitação: 7,03 anos de estudo para o setor normal e 3,97 anos para o setor subnormal.

Através das equações mincerianas de rendimentos, observou-se a existência de correlação negativa entre o setor subnormal de habitação e a renda auferida, mesmo após controlar pelas demais variáveis que influenciam a renda do indivíduo como idade, sexo, cor, escolaridade, entre outras. O coeficiente da dummy do setor de habitação indica que trabalhadores com características semelhantes possuem seus rendimentos decrescidos em cerca de $10 \%$ devido a fatores correlacionados ao fato de habitarem no setor subnormal.

Utilizando microsimulações contrafactuais, observou-se que o aumento da renda caso os trabalhadores que moram no setor subnormal tivessem o mesmo rendimento que trabalhadores semelhantes que vivem no setor normal provocaria uma redução no número de pobres nas favelas de cerca de $5 \%$, e a redução no índice de Gini do município seria de 0,607 para 0,604 .

Ao aumentar a escolaridade do setor de vilas e favelas para que tivessem uma escolaridade semelhante ao setor de não-favelas, os resultados foram muito mais expressivos. A redução no índice de pobreza foi de cerca de $20 \%$ entre os moradores de favelas e o índice de Gini para o município de Belo Horizonte declinou para 0,597.

Nota-se, assim, que tanto a redução do número de pobres como a queda da desigualdade de renda em Belo Horizonte seriam mais acentuada devido ao aumento da escolaridade que ao aumento da renda do setor subnormal relacionados aos fatores locacionais, incluindo nãoobserváveis.

Desta maneira, a expansão educacional seria uma das formas mais efetivas de diminuir a pobreza e aumentar a igualdade e mobilidade social. Assim, as políticas governamentais deveriam ter como principal foco esta expansão. 


\section{Referências}

ANTIGO, M. \& MACHADO, A. F. \& OLIVEIRA \& A. M. (2006). "Evolução do diferencial de rendimentos entre setor formal e informal no Brasil: o papel das características não observadas". Salvador: Anais do XXXIV Encontro de Economia -ANPEC, 3-5 dezembro (CD-ROM).

BARROS, R. \& MENDONÇA, R. (1995). "Os determinantes da desigualdade no Brasil”. Rio de Janeiro: IPEA, Texto para Discussão 377.

BARROS, R. \& MENDONÇA, R. (1997). "O impacto do crescimento econômico e de reduções no grau de desigualdade sobre a pobreza”. Rio de Janeiro: IPEA, Texto para Discussão 528.

BARROS, R. \& HENRIQUERS, R. \& MENDONÇA, R. (2000a). "Desigualdade Inaceitável: desigualdade e pobreza no Brasil”. In: HENRIQUES, R. (Org.). Desigualdade e pobreza no Brasil. Rio de Janeiro: IPEA, pp. 21-48.

BARROS, R. \& HENRIQUERS, R. \& MENDONÇA, R. (200ob). "Pelo fim das décadas perdidas: educação e desenvolvimento sustentado no Brasil". In: HENRIQUES, Ricardo (Org.). Desigualdade e pobreza no Brasil. Rio de Janeiro: IPEA, pp. 405-424.

CERQUEIRA, Cezar Augusto (2004). "Medidas de desigualdade de renda”. URL: http://www.cedeplar.ufmg.br/pesquisas/pbh/arquivos/ mod8parte4.pdf. Acesso em: 07/06/2007.

CRESPO, A. \& REIS, M. (2006). "Efeito diploma no Brasil". URL: www.ipea.gov.br/sites/ooo/2/boletim_mercado_de_trabalho/mt31/ o8Nota2_Anna_Mauricio.pdf. Acesso em: 05/06/2007.

FERREIRA, F. \& LITCHFIELD, J. (200o). "Desigualdade, pobreza e bem-estar social no Brasil- 1981/95”. In: HENRIQUES, R. (Org.). Desigualdade e pobreza no Brasil. Rio de Janeiro: IPEA, pp. 49-80.

FREGUGLIA, R. \& MENEZES-FILHO, N. \& SOUZA, D. (2007). "Diferenciais salariais inter-regionais, interindustriais e efeitos fixos individuais: uma análise a partir de Minas Gerais”. Estudos Econômicos, 37 (1): 129-150.

GANDRA, Rodrigo M. (2004). "O debate sobre a desigualdade de renda no Brasil: a controvérsia dos anos 70 ao pensamento hegemônico dos anos 90". URL: www.ie.ufrj.br/publicacoes/discussao/ o_debate_sobre_a_desigualdade_de_renda_no_brasil Acesso em: 05/06/ 2007 .

GOLGHER, André (2008). "Poverty in Brazil: income, material hardship and deprivation perception”. São Paulo: Anais do RSAI World Congress 2008, Março 17-19 (CD-ROM).

HECKMAN, J. \& LOCHNER, L. \& TODD, P. (2003). "Fifty years of mincer earnings regressions". Cambridge: NBER, Working Paper 9732.

HOFFMANN, Rodolfo (200o). "Mensuração da desigualdade e da pobreza no Brasil”. In: HENRIQUES, Ricardo (Org.). Desigualdade e pobreza no Brasil. Rio de Janeiro: IPEA, pp. 81-108.

ICELAND, John (2003a). Poverty in America: a handbook. Berkeley (CA): University of California Press. 
ICELAND, John (2003b). "Why poverty remains high: the role of income growth, economic inequality, and changes in family structure, 19491999". Demographyl 40 (3): 499-519.

FIBGE (2000). “Censo demográfico”. URL: http://www.ibge.gov.br. Acesso em: $23 / 05 / 2007$.

LEMOS, Celina (2004). “A questão intra-urbana. Belo Horizonte”. URL: http:/ /www.cedeplar.ufmg.br/pesquisas/pbh/arquivos/mod2parte1.pdf. Acesso em: 15/06/2007.

LIBERATO, Vânia C. (2000). "Linhas de indigência e pobreza para Belo Horizonte, RMBH e Colar Metropolitano". URL: http:// www.cedeplar.ufmg.br/pesquisas/ pbh/arquivos/mod8parte3.pdf, acessado em 15/06/2007.

MACHADO, Ana Flávia et $A L$. (2004). "Pobreza e Desigualdade em Belo Horizonte". URL: http://www.cedeplar.ufmg.br/pesquisas/pbh/ arquivos/mod9parte6.pdf. Acesso em: 20/05/2007.

MANZATTI, Marcelo (2006). "FMI: número de pobres no Brasil caiu para 23\% da população em 2005". URL: http://www.overmundo.com.br/ blogs/fmi-numero-de-pobres-no-brasil-caiu-para-23-da-populacao-em2005. Acesso em: 15/06/2007.

MENEZES-FIHO, Naércio (2002). "Equações de rendimentos: questões metodológicas”. URL: http://www.ipea.gov.br/sites/ooo/2/livros/ estruturasalarial/capitulo2_equacoes.pdf. Acesso em: 05/05/2007.

NERI, Marcelo Côrtes (2002). "Decent work and informal sector in Brazil”. URL: www.epge.fgv.br/portal/arquivo/1309.pdf .Acesso em: 05/ 06/2007.

PASTERNAK, Suzana (200o). "Favelas em São Paulo: censos, consenso e contra-sensos". Caxambu: Anais do XXIV Encontro Anual da Anpocs, 1721 de outubro (CD-ROM).

PERO, V. \& CARDOSO, A. \& ELIAS, P. (2005). "Discriminação no mercado de trabalho: o caso dos moradores de favelas cariocas". URL:

INSTITUTO PEREIRA PASSOS (2007) URL: http://www.armazemdedados.

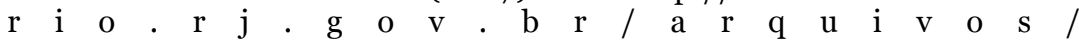
1310_discrimina\%C3\%A7\%C3\%A30\%20no\%2omercado\%20de\%20trabalho.PDF. Acesso em: 03/06/2007.

PESSOA, Samuel (2001). "Existe um problema de desigualdade regional no Brasil?” Salvador: Anais do XXIX Encontro de Economia-ANPEC, 11-14 dezembro (CD-ROM).

PINHO, Diva \& VASCONCELLOS, M. A. (2003). "Distribuição de renda no Brasil: persistência do elevado grau de desigualdade”. In: PINHO, D. e VASCONCELLOS, B. (orgs). Manual de economia. São Paulo: Saraiva, pp. 406-422.

PREFEITURA DO MUNICÍPIO DE SÃO PAULO (2002). Trabalho e Solidariedade, Violência emigração internacional na juventude. São Paulo: Secretaria do Desenvolvimento.

RAMOS, L. \& VIEIRA, M. L. (2000). "Determinantes da desigualdade de 
rendimentos no Brasil nos anos 90: discriminação, segmentação e heterogeneidade dos trabalhadores". In: HENRIQUES, R. (org.). Desigualdade e pobreza no Brasil. Rio de Janeiro: IPEA, pp. 159-176.

RAVALION, Martin (2001). "Growth, inequality and poverty: looking beyond averages”. World Development 29 (11): 1803-1815.

RESENDE, M. \& WYLLIE, R. (2006). "Retornos para e educação no Brasil: evidências empíricas adicionais". Economia Aplicada 10 (3): 349-365.

RIBEIRO, L. C. \& LAGO, L. C. (2001). “A oposição favela-bairro no espaço social do Rio de Janeiro”. São Paulo em Perspectiva 15 (1): 144-154.

ROCHA, Sônia (2000). "Opções metodológicas para a estimação de linhas de indigência e de pobreza no Brasil". Rio de Janeiro: IPEA, Texto para Discussão, 720 .

ROCHA, Sônia (2003). Pobreza no Brasil: afinal, de que se trata? Rio de Janeiro: Editora da FGV.

SACHSIDA, A. \& LOUREIRO, P. R. \& MENDONÇA, Mário Jorge C. (2004). "Um estudo sobre retorno em escolaridade no Brasil". Revista Brasileira de Economia 58 (2): 240-265.

SALDANHA JÚNIOR, R. \& AZZOLINI, P. (2001). "Estoque de conhecimento, incerteza e investimento em educação: um modelo teórico". Salvador: Anais do XXIX Encontro de Economia -ANPEC, 11-14 dezembro (CDROM).

SILVA, Regina (2000). "A voz da periferia”. URL: .http://www.naya.org.ar/ congreso 2000/ponencias/Regina_Helena_Alves_da_Silva.htm Acesso em: $18 / 06 / 2007$.

SIMÃO, Rosycler (2004). Distribuição de renda e pobreza no Estado de Minas Gerais. São Paulo: dissertação de mestrado, Escola Superior de Agricultura Luiz de Queiroz (ESALQ), Programa de Economia Aplicada.

SOARES, Sergei (2000). "O perfil da discriminação no mercado de trabalho: homens negros, mulheres brancas e mulheres negras”. URL: http:// www.aids.gov.br/ final/dh/afroatitude/desigualdes_raciais/ trabalho.pdf. Acesso em: 03/05/2007.

TROSTEL, P. \& WALKER, I. \& WOOLLEY, P. (2002). "Estimates for the economic return to schooling for 28 countries". Labour Economics 9 (1): $1-16$.

ULYSSEA, Gabriel (2006). "Informalidade no mercado de trabalho brasileiro: uma resenha da literatura". URL: www2.dbd.puc-rio.br/pergamum/ tesesabertas/ 0210688_04_cap_02.pdf. Acesso em: 05/06/2007.

Submissão: 11 de dezembro 2007

Primeira resposta: 20 de junho de 2008

Aceite: 16 de setembro de 2008 
